\title{
Career choice regret during COVID-19 among healthcare students and professionals in mainland China: a cross-sectional study
}

Guoyi Yang ${ }^{1 \dagger}$, Ling Wang ${ }^{2+}$, Jia Wang ${ }^{1}$, Zixian Geng ${ }^{1}$, Huixin Liu ${ }^{3^{*}}$ and Tao Xu ${ }^{1 *}$

\begin{abstract}
Background: The COVID-19 epidemic affected the career choice of healthcare professionals and students. Career choice regret of healthcare professionals and students during COVID-19 outbreak and its affected factors are largely unexplored.
\end{abstract}

Methods: Convenience sample of nurses, doctors, and medical students were recruited from hospitals and universities nationwide. The data collected including demographic information, professional value before and after the COVID-19 outbreak, the Connor-Davidson Resilience Scale, and career choice regret level by an online questionnaire. Multinominal logistic regression was employed to explore the factors associated with career choice regret.

Results: In total, 9322 participants of convenience sampling were enrolled in, including 5786 nurses, 1664 doctors, and 1872 medical students. 6.7\% participants had career choice regret. Multinominal logistic regression analysis showed, compared to participants with no regret, that as levels of psychological resilience increased, the odds of experiencing career choice regret decreased ( $O R=0.95,95 \% \mathrm{Cl} 0.94-0.96)$, while participants with lower professional value evaluation after the COVID-19 outbreak had higher probability to experience career choice regret $(\mathrm{OR}=1.55,95 \% \mathrm{Cl} 1.50-1.61)$. Medical students were more likely to regret than nurses (OR $=1.65,95 \% \mathrm{Cl} 1.20-2.28)$, participants whose career/major choice was not their personal ideal had higher risk of experience career choice regret $(O R=1.59,95 \% \mathrm{Cl} 1.29-1.96)$, while participants who were very afraid of the coronavirus had higher risk to experience career choice regret then participants with no fear at all $(\mathrm{OR}=2.00,95 \% \mathrm{Cl} 1.24-3.21)$.

As for the medical students, results indicated that medical students major in nursing and undergraduates had higher risk to experience career choice regret compared to medical students major in clinical medicine and postgraduate (Master or PhD), with an odds ratios of $2.65(95 \% \mathrm{Cl} 1.56-4.49)$ and 6.85 (95\% Cl 2.48-18.91) respectively.

\footnotetext{
*Correspondence: liuhuixin@bjmu.edu.cn; xutao@pkuph.edu.cn

${ }^{\dagger}$ Guoyi Yang and Ling Wang are co-first authors.

${ }^{1}$ Urology Department, Peking University People's Hospital, No. 11

Xizhimen South Street Xicheng District, Beijing 100044, China

${ }^{3}$ Department of Clinical Epidemiology and Biostatistics, Peking University

People's Hospital, Beijing, China

Full list of author information is available at the end of the article
}

(C) The Author(s) 2021. Open Access This article is licensed under a Creative Commons Attribution 4.0 International License, which permits use, sharing, adaptation, distribution and reproduction in any medium or format, as long as you give appropriate credit to the original author(s) and the source, provide a link to the Creative Commons licence, and indicate if changes were made. The images or other third party material in this article are included in the article's Creative Commons licence, unless indicated otherwise in a credit line to the material. If material is not included in the article's Creative Commons licence and your intended use is not permitted by statutory regulation or exceeds the permitted use, you will need to obtain permission directly from the copyright holder. To view a copy of this licence, visit http://creativecommons.org/licenses/by/4.0/. The Creative Commons Public Domain Dedication waiver (http://creativeco mmons.org/publicdomain/zero/1.0/) applies to the data made available in this article, unless otherwise stated in a credit line to the data. 
Conclusions: A minority of healthcare professionals and medical students regretted their career choices during the COVID-19 outbreak. Enhance personal psychological resilience and professional value would helpful to reduce career choice regret among healthcare professionals and students during pandemic.

Keywords: COVID-19;career choice regret, Healthcare professionals;medical students, Psychological resilience, Professional value

\section{Background}

The coronavirus disease 2019(COVID-19) is a severe acute respiratory infection caused by SARS-CoV-2 which is high transmission. it has spread to 200 countries and has been declared a global pandemic by the World Health Organization (WHO). Globally, as of 24 November 2020, there have been more than 58 million confirmed cases of COVID-19, including 1385 thousand deaths, reported to WHO (1). With the rapid and extensive spread, doctors and nurses have been confronted with mounting challenges that they have not been faced before.

They encounter work difficulties due to lack of resources and threats to the safety of their loved ones (2) and the highest risk of being infected (3). Moreover, the COVID-19 epidemic had negative impacts on the psychology of healthcare professionals. Studies have showed during the COVID-19 outbreak, healthcare professionals dealing with COVID-19 were under increased levels of anxiety, depression, and stress (4, 5). The epidemic also has increased medical students' perceptual awareness of the high-risk characteristics of medical and health services (6).

Previous studies showed that depressive symptoms and higher levels of burnout were related to decrease medical career interest, increased career choice regret (7-9). CNN News reported that affected by the epidemic, some American nurses were overwhelmed to strike (10).

Although previous studies have focused on careerchoice regret among healthcare professionals and medical students, most have not been in the context of the COVID-19 outbreak $(8,11-13)$. Only one study investigated the impact of COVID-19 outbreak on the career preferences of medical students in China (7), focusing only on a particular specialty but not on a broader range of doctors, nurses and medical students who are potential doctors or nurses. We conducted the following study with the aims of bridging this gap, to depict the situation of career choice regret among healthcare professionals and students during COVID19 pandemic and to explore strategies to prevent career choice regret among healthcare professionals and students.

\section{Methods}

\section{Study design, setting, and participants}

A cross-sectional study was conducted from April 23 to May 20,2020. Convenient sampling of doctors and nurses in the hospital and medical college students majoring in clinical medicine and nursing in mainland China were recruited nationwide online. All participants were invited to complete the questionnaire online via Questionnaire Star (https://www.wjx.cn). This study complies with the statement of strengthening the reporting of observational studies in epidemiology (STROBE).

\section{Measurements}

A research group with one physician, two nurses and one epidemiologist were set up to develop the questionnaire. The questions and answer options for the preliminary questionnaire were developed according to the research objective and extensive literature review results. Then an expert panel of two clinical experts, two nursing experts and one epidemiologist were invited to review and revise the preliminary questionnaire. Finally, a pilot study among 40 doctors and nurses and 20 students was conducted before the survey. The questionnaire was further modified according to the feedback of the pilot study to make sure all the questions were clear and unambiguous.

The online questionnaire collected the following information, general information, professional value before and after the outbreak of COVID-19, the Connor-Davidson Resilience scale and one question about career choice regret affected by the COVID-19.Details of each part are as described below.

\section{General information}

The following information were collected from all the participants, including gender, age, educational level, the reason of career choice for healthcare professionals/ major choice for medical students, whether have experienced verbal violence or physical violence during medical practicing, the willingness to participate in treatment or nursing during public health emergencies and the degree of fear of the coronavirus. In addition to the above, doctors and nurses were also asked if they participated in the treatment or nursing of patients with COVID-19, and medical students were asked 
whether their current major was the first choice, whether have had started internship in the hospital.

\section{Professional value before and after the COVID-19 outbreak} This part contains 5 items to investigate the professional value of the participants before and after the outbreak of COVID-19. Each item using a 5- Likert response scale, response options ranged from "nonconformity" to "full conformity" (score brange,5-25) and a higher score indicated lower professional value evaluation.

\section{The Connor-Davidson resilience scale (CD-RISC)}

The scale was developed by Connor and Davidson (14) and was revised by Yu (15), comprises 3 dimensions (competency, toughness, and adaptability), 25 items rated on a 5-point scale (0-4), with higher scores reflecting greater resilience. The internal consistency coefficient of the questionnaire is 0.89 , which has good reliability and validity.

\section{Career choice regret}

This part contains one question for all the participants "after the outbreak of COVID-19, I regret the choice I made about my career". Response options were "strongly agree", "agree", "neutral", "disagree" and"strongly disagree"; responses of "strongly agree" or "agree" indicated with career choice regret, "disagree" and"strongly disagree" indicated without career choice regret.

\section{Statistical analysis}

Categorical data are presented as frequencies and percent, continuous data are described by mean and standard deviation or median and interquartile range (IQR) as appropriate. Mann-Whitney U or KruskalWallis $\mathrm{H}$ test were performed to test the association of career choice regret with the following categorical variables, identity, gender, whether experienced physical violence during practicing, whether experienced verbal violence during practicing, the reason of career/major choice, major, work intention after graduation, whether

Table 1 Personal and professional characteristics of participants $(n=9322)$

\begin{tabular}{|c|c|c|c|c|}
\hline \multirow[b]{2}{*}{ Characteristics } & \multicolumn{2}{|c|}{ healthcare professionals } & \multicolumn{2}{|l|}{ medical students } \\
\hline & nurses & doctors & Clinical Medicine & nursing \\
\hline \multicolumn{5}{|l|}{ Gender } \\
\hline Male & 192(3.3\%) & $1018(61.2 \%)$ & $468(42.5 \%)$ & 118(15.3\%) \\
\hline Female & $5594(96.7 \%)$ & $646(38.8 \%)$ & $632(57.5 \%)$ & $654(84.7 \%)$ \\
\hline Age & $33.02 \pm 7.42$ & $38.65 \pm 8.27$ & $21.60 \pm 3.02$ & $20.60 \pm 2.81$ \\
\hline \multicolumn{5}{|l|}{ Educational level } \\
\hline Below Bachelor degree & 1907(33.0\%) & $60(3.6 \%)$ & 0 & $135(17.5 \%)$ \\
\hline Bachelor degree & $3765(65.1 \%)$ & $773(46.5 \%)$ & $897(81.5 \%)$ & $598(77.5 \%)$ \\
\hline Master's degree & $114(2.0 \%)$ & $506(30.4 \%)$ & $149(13.5 \%)$ & $37(4.8 \%)$ \\
\hline Doctorate & 0 & $325(19.5 \%)$ & $54(4.9 \%)$ & $2(0.3 \%)$ \\
\hline \multicolumn{5}{|c|}{ Work intention after graduation } \\
\hline Tertiary hospital & N/A & N/A & $972(88.4 \%)$ & $642(83.2 \%)$ \\
\hline Primary hospital & N/A & N/A & $69(6.3 \%)$ & $43(5.6 \%)$ \\
\hline Others & N/A & N/A & $59(5.4 \%)$ & $87(11.3 \%)$ \\
\hline \multicolumn{5}{|c|}{ Whether current major is the first choice } \\
\hline Yes & N/A & N/A & 1025(93.2\%) & $456(59.1 \%)$ \\
\hline No & N/A & N/A & $75(6.8 \%)$ & $316(40.9 \%)$ \\
\hline \multicolumn{5}{|c|}{ Whether have had started internship in the hospital } \\
\hline Yes & N/A & N/A & $318(28.9 \%)$ & $431(55.8 \%)$ \\
\hline No & N/A & N/A & $782(71.7 \%)$ & $341(44.2 \%)$ \\
\hline \multicolumn{5}{|c|}{ Reason of major/career choice } \\
\hline \multicolumn{5}{|l|}{ Personal ideal } \\
\hline Yes & $996(59.9 \%)$ & $2048(35.4 \%)$ & $825(75.0 \%)$ & $396(51.3 \%)$ \\
\hline No & $668(40.1 \%)$ & $3738(64.6 \%)$ & $275(25.0 \%)$ & $376(48.7 \%)$ \\
\hline \multicolumn{5}{|l|}{ Family wishes } \\
\hline Yes & $826(49.6 \%)$ & $2824(48.8 \%)$ & $567(51.5 \%)$ & $358(46.4 \%)$ \\
\hline No & $838(50.4 \%)$ & $2962(51.2 \%)$ & $553(48.5 \%)$ & $414(53.6 \%)$ \\
\hline
\end{tabular}


current major was the first choice, whether have had started internship in the hospital, whether participated in the treatment or nursing of patients with COVID19. Test for Linear Trend was used to test the association of career choice regret with the fear level after the COVID-19 outbreak. Paired t test or Wilcoxon signedrank test were used to measure the change of professional value during COVID-19. Multinomial logistic regression analysis was performed to identify factors associated with regret of choice of career among all the participants, a subgroup analysis was also done among potential healthcare professionals (medical students). All statistical analyses were conducted in SPSS version 26.0 (IBM, Chicago, IL, USA), and $P<0.05$ was considered to be statistically significant.

\section{Ethics statement}

This study was approved by Peking University People's Hospital Ethical Committee [No:2020PHB181-01]. The online survey was anonymous. Informed consent was obtained from all subjects or, if subjects are under 18, from a parent and/or legal guardian when they accessed the online survey.

\section{Results}

\section{Participants' characteristics}

A total of 9322 participants were finally included, consisted of 5786 nurses, 1664 doctors, and 1872 medical students. Among the medical students, 1100 are major in clinical medicine and 772 are major in nursing. Among the healthcare professionals, 2482 were involved in the treatment or nursing the patient with COVID-19, accounting for $33.3 \%$. The average age of participants was 31.65 years; 1796 were male (19.3\%) and 7526 were female $(80.7 \%$, Table 1$)$.

\section{The level of career choice regret among healthcare professionals and potential healthcare professionals}

There were 5506 of 9322 respondents (59.1\%) reported that they had no regret of their choice of career, while

Table 2 Univariate analysis of influencing factors of career choice regret after COVID-19 outbreak $(n=9322)$

\begin{tabular}{|c|c|c|c|c|c|c|}
\hline \multirow[t]{2}{*}{ Variable } & \multicolumn{6}{|c|}{ I regret the career choice I made } \\
\hline & $\begin{array}{l}\text { strongly } \\
\text { disagree }\end{array}$ & disagree & neutral & agree & strongly agree & $P^{*}$ \\
\hline Identity & & & & & & $<0.001$ \\
\hline Doctor & 277 & 720 & 542 & 79 & 46 & \\
\hline Nurse & 1075 & 2240 & 2071 & 259 & 141 & \\
\hline Student & 391 & 803 & 579 & 73 & 26 & \\
\hline Gender & & & & & & 0.027 \\
\hline Male & 353 & 764 & 543 & 92 & 44 & \\
\hline Female & 1390 & 2999 & 2649 & 319 & 169 & \\
\hline Whether experienced physical violence & & & & & & $<0.001$ \\
\hline Yes & 282 & 622 & 592 & 125 & 72 & \\
\hline No & 1461 & 3141 & 2600 & 286 & 141 & \\
\hline Whether experienced verbal violence & & & & & & $<0.001$ \\
\hline Yes & 910 & 2174 & 1945 & 301 & 160 & \\
\hline No & 833 & 1589 & 1247 & 110 & 53 & \\
\hline The reason of career/major choice is personal ideal & & & & & & $<0.001$ \\
\hline Yes & 1122 & 1954 & 1007 & 110 & 72 & \\
\hline No & 621 & 1809 & 2185 & 301 & 141 & \\
\hline The reason of career/major choice is family will & & & & & & $<0.001$ \\
\hline Yes & 769 & 1880 & 1607 & 213 & 106 & \\
\hline No & & & & & & \\
\hline Afraid of coronavirus degree & & & & & & $<0.001$ \\
\hline Very afraid & 78 & 77 & 118 & 35 & 36 & \\
\hline Afraid & 175 & 420 & 488 & 76 & 33 & \\
\hline General afraid & 607 & 1842 & 1687 & 194 & 85 & \\
\hline Not afraid & 518 & 1125 & 708 & 82 & 34 & \\
\hline Not afraid at all & 365 & 299 & 191 & 24 & 25 & \\
\hline
\end{tabular}

Note:*P for trend 
624 of 9322 respondents (6.7\%) reported that they had career choice regret. For the question about whether the outbreak of COVID-19 made them regret the choice they made about their career, $4.5 \%$ reported "agree" and $2.5 \%$ reported "strongly agree" among healthcare professionals, while for medical students, $3.9 \%$ and $1.4 \%$ reported "agree" and "strongly agree".

\section{Factors associated with career choice regret}

\section{after the COVID-19 outbreak in a univariate analysis}

The healthcare professionals who participated in the treatment or nursing of patients with COVID-19 have lower career choice regret after the COVID-19 outbreak $(\mathrm{Z}=-2.726, P=0.006)$. For all the participants, in the univariate analysis (Table 2), career choice regret after the COVID-19 outbreak was associated with identity, gender, having experienced physical or verbal violence, the reason of career/major choice was personal ideal or family will.

As for medical students, univariate analysis results showed that, career choice regret after the COVID19 outbreak was associated with their current major, work intention after graduation, whether their current major was the first choice, whether have had started internship in the hospital, willingness to participate in treatment or nursing facing public health emergencies (Table 3).

\section{Factors associated with career choice regret} after the COVID-19 outbreak in a multi-factor analysis Multinominal logistic regression results (Table 4) showed that as levels of psychological resilience increased, the odds of experiencing career choice regret decreased ( $\mathrm{OR}=0.95,95 \% \mathrm{CI} 0.94-0.96)$, while participants with higher professional value score (means lower professional value evaluation) had higher probability to experience career choice regret $(\mathrm{OR}=1.55,95 \%$ CI $1.50-1.61)$. Medical students were more likely to regret about their career choice than nurses $(\mathrm{OR}=1.65,95 \%$ CI $1.20-2.28)$, participants whose career/major choice was not according to their personal ideal had higher risk of experience career choice regret $(\mathrm{OR}=1.59,95 \%$ CI $1.29-1.96)$, participants who have not experienced physical violent medical incidents had lower probability to experience career choice regret $(\mathrm{OR}=0.67,95 \%$ CI $0.54-0.85)$, while participants who were very afraid of the coronavirus had higher risk to experience career choice

Table 3 Factors of associated career choice regret after COVID-19 outbreak among medical students $(n=1872)$

\begin{tabular}{|c|c|c|c|c|c|c|}
\hline \multirow[t]{2}{*}{ Variable } & \multicolumn{6}{|c|}{ I regret the career choice I made } \\
\hline & $\begin{array}{l}\text { strongly } \\
\text { disagree }\end{array}$ & disagree & neutral & agree & strongly agree & $P^{*}$ \\
\hline \multicolumn{6}{|l|}{ Educational level } & $<0.001$ \\
\hline Below Bachelor degree & 39 & 47 & 43 & 4 & 2 & \\
\hline Bachelor degree & 326 & 649 & 457 & 44 & 19 & \\
\hline Above Bachelor degree & 26 & 107 & 79 & 25 & 5 & \\
\hline \multicolumn{6}{|l|}{ Major } & $<0.001$ \\
\hline Nursing & 101 & 306 & 310 & 39 & 16 & \\
\hline Clinical medicine & 101 & 306 & 310 & 39 & 16 & \\
\hline \multicolumn{6}{|l|}{ Work intention after graduation } & $<0.001$ \\
\hline Tertiary hospital & 349 & 716 & 482 & 48 & 19 & \\
\hline Primary hospital & 24 & 47 & 32 & 8 & 1 & \\
\hline Others & 18 & 40 & 65 & 17 & 6 & \\
\hline \multicolumn{6}{|l|}{ Whether major is the first choice } & $<0.001$ \\
\hline Yes & 360 & 655 & 397 & 52 & 17 & \\
\hline No & 31 & 148 & 182 & 21 & 9 & \\
\hline \multicolumn{6}{|l|}{ Whether is interning in the hospital } & $<0.001$ \\
\hline Yes & 125 & 323 & 243 & 45 & 13 & \\
\hline No & 266 & 480 & 336 & 28 & 13 & \\
\hline \multicolumn{6}{|c|}{ For public health emergencies, will you participate in the treatment or nursing? } & $<0.001$ \\
\hline Definitely will & 216 & 206 & 97 & 12 & 10 & \\
\hline Will & 135 & 397 & 228 & 27 & 4 & \\
\hline Not necessarily & 37 & 197 & 238 & 32 & 6 & \\
\hline Not will & 1 & 3 & 14 & 2 & 4 & \\
\hline Definitely not & 2 & 0 & 2 & 0 & 2 & \\
\hline
\end{tabular}


Table 4 Factors associated with career choice regret after the COVID-19 epidemic in multinominal logistic regression $(n=9322)$

\begin{tabular}{|c|c|c|c|c|c|c|}
\hline \multicolumn{2}{|c|}{ Career choice regret } & \multirow{2}{*}{$\begin{array}{l}\boldsymbol{\beta} \\
-5.58\end{array}$} & \multirow{2}{*}{$\begin{array}{l}\text { SE } \\
0.55\end{array}$} & \multirow{2}{*}{$\begin{array}{l}\text { Wald } \\
103.16\end{array}$} & \multirow[t]{2}{*}{$\mathrm{OR}(95 \% \mathrm{Cl})$} & \multirow{2}{*}{$\frac{P}{<0.001}$} \\
\hline \multirow{33}{*}{$\begin{array}{l}\text { With career choice } \\
\text { regret }\end{array}$} & Intercept & & & & & \\
\hline & Total score of psychological resilience & & & & & \\
\hline & & -0.05 & 0.00 & 131.32 & $0.95(0.94-0.96)$ & $<0.001$ \\
\hline & Age & -0.01 & 0.01 & 2.12 & $0.99(0.98-1.00)$ & 0.146 \\
\hline & Total score of professional value after th & -19 outbreak & & & & \\
\hline & & 0.44 & 0.017 & 652.894 & $1.55(1.50-1.61)$ & $<0.001$ \\
\hline & Change of professional value & & & & & \\
\hline & & -0.15 & 0.02 & 48.63 & $0.86(0.82-0.90)$ & $<0.001$ \\
\hline & Identity & & & & & \\
\hline & Student & 0.50 & 0.16 & 9.48 & $1.65(1.20-2.28)$ & 0.002 \\
\hline & Doctor & -0.30 & 0.16 & 3.47 & $0.74(0.54-1.02)$ & 0.063 \\
\hline & Nurse & reference & & & & \\
\hline & Gender & & & & & \\
\hline & Female & -0.17 & 0.15 & 1.38 & $0.84(0.63-1.12)$ & 0.24 \\
\hline & Male & reference & & & & \\
\hline & The reason of career/major choice is pe & leal & & & & \\
\hline & No & 0.47 & 0.11 & 18.99 & $1.59(1.29-1.96)$ & $<0.001$ \\
\hline & Yes & reference & & & & \\
\hline & The reason of career/major choice is far & & & & & \\
\hline & No & 0.04 & 0.09 & 0.20 & $1.04(0.87-1.25)$ & 0.652 \\
\hline & Yes & reference & & & & \\
\hline & Whether experienced physical violence & & & & & \\
\hline & No & -0.40 & 0.12 & 11.45 & $0.67(0.54-0.85)$ & 0.001 \\
\hline & Yes & reference & & & & \\
\hline & Whether experienced verbal violence & & & & & \\
\hline & No & 0.12 & 0.12 & 1.00 & $1.13(0.89-1.43)$ & 0.317 \\
\hline & Yes & reference & & & & \\
\hline & Afraid of coronavirus degree & & & & & \\
\hline & Very afraid & 0.69 & 0.24 & 8.20 & $2.00(1.24-3.21)$ & 0.004 \\
\hline & Afraid & 0.39 & 0.20 & 3.64 & $1.47(0.99-2.18)$ & 0.056 \\
\hline & General afraid & 0.12 & 0.18 & 0.42 & $1.12(0.79-1.59)$ & 0.515 \\
\hline & Not afraid & -0.13 & 0.19 & 0.43 & $0.88(0.60-1.29)$ & 0.514 \\
\hline & Not afraid at all & reference & & & & \\
\hline \multirow[t]{16}{*}{ neutral } & Intercept & -1.87 & 0.30 & 39.15 & & $<0.001$ \\
\hline & Total score of psychological resilience & & & & & \\
\hline & & -0.04 & 0.00 & 294.02 & $0.96(0.95-0.96)$ & $<0.001$ \\
\hline & Age & -0.02 & 0.00 & 18.18 & $0.98(0.98-0.99)$ & $<0.001$ \\
\hline & Total score of professional value after th & -19 outbreak & & & & \\
\hline & & 0.25 & 0.01 & 687.12 & $1.29(1.26-1.31)$ & $<0.001$ \\
\hline & Change of professional value & & & & & \\
\hline & & -0.04 & 0.01 & 12.35 & $0.96(0.93-0.98)$ & $<0.001$ \\
\hline & Identity & & & & & \\
\hline & Student & 0.16 & 0.08 & 3.50 & $1.17(0.99-1.38)$ & 0.061 \\
\hline & Doctor & 0.02 & 0.09 & 0.03 & $1.02(0.86-1.20)$ & 0.855 \\
\hline & Nurse & reference & & & & \\
\hline & Gender & & & & & \\
\hline & Female & 0.08 & 0.08 & 1.12 & $1.09(0.93-1.27)$ & 0.29 \\
\hline & Male & reference & & & & \\
\hline & The reason of career/major choice is pe & leal & & & & \\
\hline
\end{tabular}


Table 4 (continued)

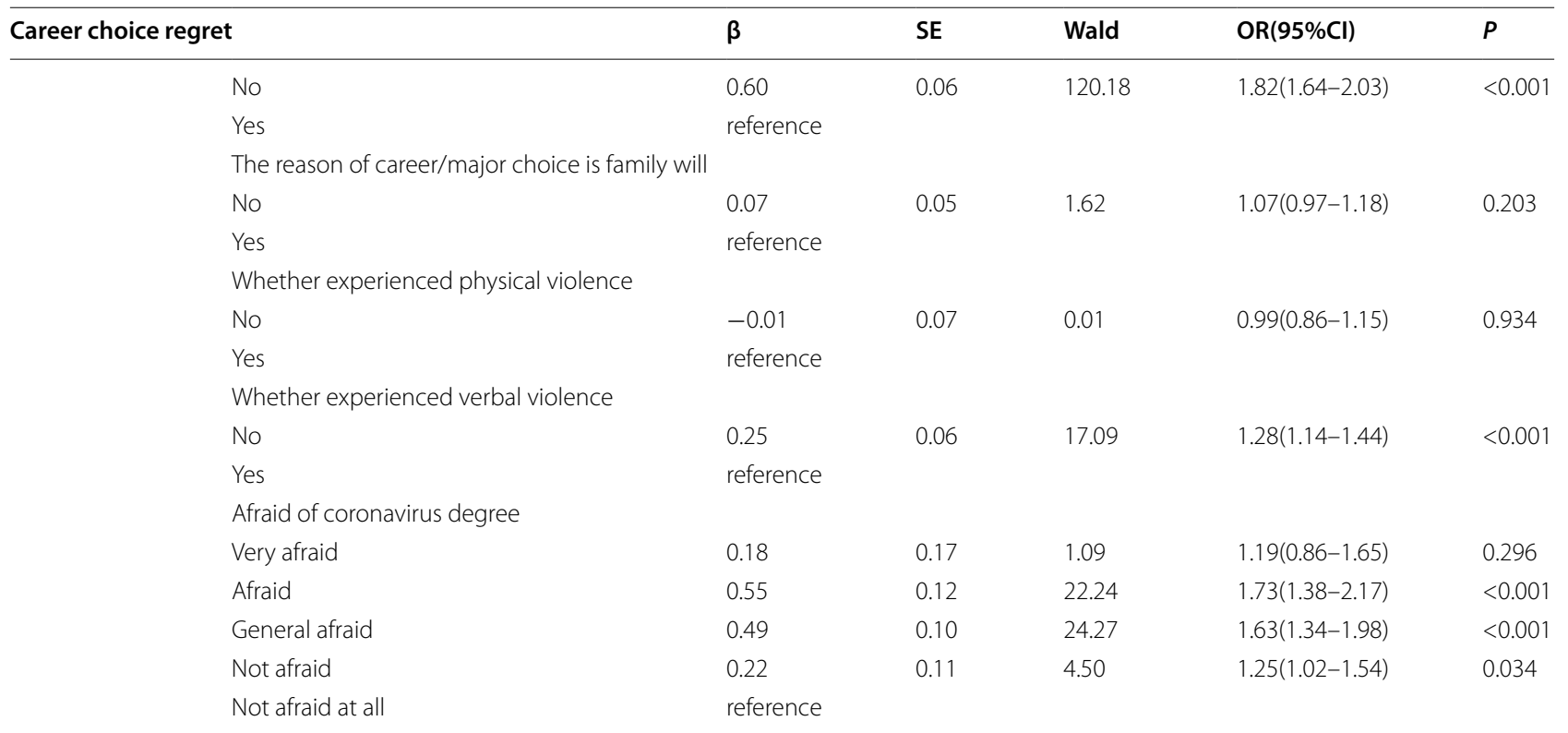

\# The reference category is without career choice regret

regret then participants with no fear at all $(\mathrm{OR}=2.00$, 95\% CI 1.24-3.21).

As for the medical students, multinominal logistic regression analysis results (Table 5 ) indicated that medical students major in nursing and undergraduates had higher risk to experience career choice regret compared to medical students major in clinical medicine and postgraduate (Master or $\mathrm{PhD}$ ), with an odds ratios of $2.65(95 \%$ CI $1.56-4.49)$ and $6.85(95 \%$ CI $2.48-18.91)$ respectively.

\section{Discussion}

This nationwide research investigated the current situation and influencing factors of the career choice regret of healthcare professionals and medical students during the COVID19 epidemic. Although the epidemic has brought challenges to healthcare, but our research showed only $6.7 \%$ healthcare professionals and medical students regret about their career choice. This situation is similarly to previous pandemic (16). Despite the initial shock, the health professionals in China appear to exhibit high levels of commitment and professionalism. The increasing knowledge about preventing and dealing with the disease, and the development of more specific procedural and treatment protocols, alongside educational activities, contributed to improving the morale of healthcare workers dealing with the pandemic.

Our research shows that the degree of regret of medical students' career choice is lower than that of medical staff, and it is statistically significant. Among medical students, those who have had started internship have more risk to experience career choice regret than those who have not entered clinical internship. It is possible that the COVID19 pandemic resulted in cancellation of medical student clinical rotations (17). Therefore, educators should intervene and cultivate their professional values after students started internship, and targeted efforts by medical schools to address these concerns through enhanced virtual curriculum development and advising strategies will become increasingly important. So as to reduce their professional regret and reserve talents for the medical career.

The multivariate analysis showed that the professional value was the influence factor of career choice regret during the COVID-19 outbreak. The population with higher professional value showed lower level of regret. Although the professional value has declined slightly after the epidemic, it was still at a high level, and the impact on career choice regret was still positive. Professional value identification plays an important role in career choice. Opportunity to help and care for others as the core professional value of the medicine was the main reason of the students and nurses to undertake nursing $(18,19)$, and the realization of the professional value of healthcare professionals enables them to insist on their own choice (20) and even to recommend their relatives to work in the health center (21). Therefore, cultivating the professional value of medical staff in peacetime was more conducive to reducing the impact on the career choice regret of medical staff after major public health incidents. 
Table 5 Factors associated with career choice regret after the COVID-19 epidemic in multinominal logistic regression among medical students $(n=1872)$

\begin{tabular}{|c|c|c|c|c|c|c|}
\hline \multicolumn{2}{|c|}{ Career choice regret } & \multirow{2}{*}{$\begin{array}{l}\text { B } \\
-2.37\end{array}$} & \multirow{2}{*}{$\begin{array}{l}\text { SE } \\
0.57\end{array}$} & \multirow{2}{*}{$\begin{array}{l}\text { Wald } \\
17.12\end{array}$} & \multirow[t]{2}{*}{ OR(95\% Cl) } & \multirow{2}{*}{$\frac{P}{<0.001}$} \\
\hline With career choice & Intercept & & & & & \\
\hline & Major & & & & & \\
\hline & Nursing & 0.97 & 0.27 & 13.03 & $2.65(1.56-4.49)$ & $<0.001$ \\
\hline & Clinical Medicine & reference & & & & \\
\hline & Work intention after graduation & & & & & \\
\hline & Tertiary hospital & -1.52 & 0.29 & 27.16 & $0.22(0.12-0.39)$ & $<0.001$ \\
\hline & Primary hospital & -0.62 & 0.45 & 1.90 & $0.54(0.22-1.30)$ & 0.168 \\
\hline & Others & reference & & & & \\
\hline & Whether is interning in the hospital & & & & & \\
\hline & No & -0.2110 & 0.27 & 0.62 & $0.81(0.48-1.37)$ & 0.433 \\
\hline & Yes & reference & & & & \\
\hline & Whether major is the first choice & & & & & \\
\hline & No & 0.47 & 0.27 & 3.04 & $1.59(0.94-2.69)$ & 0.081 \\
\hline & Yes & reference & & & & \\
\hline & Educational level & & & & & \\
\hline & Below Bachelor degree & 0.48 & 0.49 & 0.96 & $1.61(0.62-4.16)$ & 0.327 \\
\hline & Bachelor degree & 1.92 & 0.52 & 13.80 & $6.85(2.48-18.91)$ & $<0.001$ \\
\hline & Master's degree or doctorate & reference & & & & \\
\hline \multirow[t]{18}{*}{ neutral } & Intercept & -0.83 & 0.30 & 7.73 & & 0.005 \\
\hline & Major & & & & & \\
\hline & Nursing & 0.72 & 0.13 & 29.62 & $2.05(1.58-2.65)$ & $<0.001$ \\
\hline & Clinical Medicine & reference & & & & \\
\hline & Work intention after graduation & & & & & \\
\hline & Tertiary hospital & -0.72 & 0.20 & 13.43 & $0.49(0.33-0.71)$ & $<0.001$ \\
\hline & Primary hospital & -0.69 & 0.29 & 5.66 & $0.50(0.29-0.89)$ & 0.017 \\
\hline & Others & reference & & & & \\
\hline & Whether is interning in the hospital & & & & & \\
\hline & No & 0.17 & 0.14 & 1.46 & $1.18(0.90-1.54)$ & 0.226 \\
\hline & Yes & reference & & & & \\
\hline & Whether major is the first choice & & & & & \\
\hline & No & 0.62 & 0.14 & 20.63 & $1.86(1.42-2.44)$ & $<0.001$ \\
\hline & Yes & reference & & & & \\
\hline & Educational level & & & & & \\
\hline & Below Bachelor degree & 0.15 & 0.23 & 0.42 & $1.16(0.74-1.80)$ & 0.518 \\
\hline & Bachelor degree & 0.76 & 0.26 & 8.24 & $2.13(1.27-3.56)$ & 0.004 \\
\hline & Master's degree or doctorate & reference & & & & \\
\hline
\end{tabular}

\# The reference category is without career choice regret

When the COVID-19 outbreak, healthcare professionals directly participated in the treatment or nursing of the patient with COVID-19. They were facing great mental and physical pressure. Regarding the psychological suffering of individuals, an important key psycho-social factor was psychological resilience. Our research showed that the stronger a person's psychological resilience was, the lower his regret for career choices when facing the COVID-19 epidemic.
Resilience plays a decisive role in the response of individuals under pressure and can help them deal with difficulties and adverse circumstances more effectively (22). The previous study showed psychosocial strengths play a significant role in subsiding the risk associated with severity of disease when facing COVID-19 (23). Therefore, it is believed that higher levels of resilience can protect a person from pressure and reduce the risk of regretting career choices. 


\section{Conclusion}

During COVID-19 outbreak in China, the degree of career choices among healthcare professionals and medical students was low. Career intention is personal ideal, experienced physical or verbal violence, higher psychological resilience, higher professional value after the epidemic, lower change of professional value were associated with a lower career choice regret. Medical students' career choice regret was lower than the health professionals. For the medical students, having entered the clinical practice stage, major was not the first choice for college entrance examination volunteers, work intention after graduation wasn't in hospital had higher level of regret.

\section{Limitations of this study}

Our study is limited in several ways. First, as a crosssectional design, this study could only evaluate the career choice regret at the time without the longitudinal observation of the subjects, so follow up is warranted in the future. Second, the survey used convenience sample recruited online, which could result in selection bias. However, the findings of this study may have some generalizability given the large sample and with the $50 \mathrm{EPV}(50$ events per predictor variable) of the multinomial logistic regression, we believe the regression model have good predictive performance. Third, The subjects included in this study were those who are currently doctors, nurses, or medical students after the COVID-19 outbreak, healthcare professionals who have changed careers after the COVID-19 outbreak were not included in this survey, also we did not collect the information about the participants' former career, there might be some participants who were not healthcare professionals before and engage in healthcare after the COVID-19 outbreak, which might causes bias of the results. Fourth, although we did a literature review and discussed with experts at the proposal stage, there could be some potential unobserved confounding factors that were not controlled.

\section{Acknowledgements}

We thank the health professionals and medical students who participated in this survey and thank the hospital and university providing us.

\section{Authors' contributions}

All authors contributed to the conception and design of the study, GYY, $H X L$, JW, ZXG collected and collated data, GYY, HXL, LW, TX analyzed and interpreted data, GYY, LW, JW, ZXG wrote the first draft of the manuscript, $H X L, T X$ revised the final version of the manuscript. All authors read and approved the final manuscript.

\section{Funding}

There is no funding support for this research.

\section{Availability of data and materials}

The datasets used and/or analysed during the current study are available from the corresponding author on reasonable request.

\section{Declarations}

Ethics approval and consent to participate

This study was approved by Peking University People's Hospital Ethical Committee [No:2020PHB181-01]. The online survey was anonymous. Informed consent was obtained from all subjects or, if subjects are under 18, from a parent and/or legal guardian when they accessed the online survey.

\section{Consent for publication}

Not applicable.

\section{Competing interests}

The authors declare that they have no competing interests.

\section{Author details}

${ }^{1}$ Urology Department, Peking University People's Hospital, No. 11 Xizhimen South Street Xicheng District, Beijing 100044, China. ${ }^{2}$ Nursing Department, Peking University People's Hospital, No. 11 Xizhimen South Street Xicheng District, Beijing 100044, China. ${ }^{3}$ Department of Clinical Epidemiology and Biostatistics, Peking University People's Hospital, Beijing, China.

Received: 20 January 2021 Accepted: 4 October 2021

Published online: 18 October 2021

\section{References}

1. Coronavirus disease (COVID-19) https://www.who.int/emergencies/ diseases/novel-coronavirus-2019.

2. Robblee J, Buse DC, Halker Singh RB, Schusse CM, Riggins N, Rayhill $M L$, et al. Eleven things not to say to healthcare professionals during the COVID-19 pandemic. Headache. 2020.

3. Ağalar C, Öztürk ED. Protective measures for COVID-19 for healthcare providers and laboratory personnel. Turkish journal of medical sciences. 2020;50(Si-1):578-84.

4. Tsamakis K, Rizos E, Manolis AJ, Chaidou S, Kympouropoulos S, Spartalis E, et al. COVID-19 pandemic and its impact on mental health of healthcare professionals. Experimental and Therapeutic Medicine. 2020;19(6):3451-3.

5. Kang L, Ma S, Chen M, Yang J, Wang Y, Li R, et al. Impact on mental health and perceptions of psychological care among medical and nursing staff in Wuhan during the 2019 novel coronavirus disease outbreak: a cross-sectional study. Brain Behav Immun. 2020;87:11-7

6. Ikhlaq A, Bint ERH, Bashir I, Ijaz F. Awareness and Attitude of Undergraduate Medical Students towards 2019-novel Corona virus. Pak J Med Sci. 2020;36(Covid19-s4):S32-s6.

7. Hu L, Wu H, Zhou W, Shen J, Qiu W, Zhang R, et al. Positive impact of COVID-19 on career choice in pediatric medical students: a longitudinal study. Translational Pediatrics. 2020;9(3):243-52.

8. Tian L, Pu J, Liu Y, Zhong X, Gui S, Song $X$, et al. Relationship between burnout and career choice regret among Chinese neurology postgraduates. BMC Medical Education. 2019;19(1):162.

9. Grace MK. Depressive symptoms, burnout, and declining medical career interest among undergraduate pre-medical students. Int J Med Educ. 2018:9:302-8.

10. Paul P. Murphy, Young R, Carpenter J. Detroit hospital nurses refuse to work without more help, ordered to leave: Cable News Network; 2020 [updated April 8, 2020. Available from: https://edition.cnn.com/ 2020/04/07/us/detroit-nurses-sinai-grace-coronavirus/index.html.

11. Dyrbye LN, Burke SE, Hardeman RR, Herrin J, Wittlin NM, Yeazel M, et al. Association of Clinical Specialty with Symptoms of burnout and career choice regret among US resident physicians. Jama. 2018;320(11):1114-30.

12. Dyrbye L, West $C$, Johnson P, Cipriano P, Peterson C, Beatty D, et al. Original research: an investigation of career choice regret among American nurses. Am J Nurs. 2020;120(4):24-33.

13. Zhou W, Pu J, Zhong X, Yang W, Teng T, Fan L, et al. Overlap of burnout-depression symptoms among Chinese neurology graduate students in a national cross-sectional study. BMC Med Education. 2021;21(1):83. 
14. Connor KM, Davidson JR. Development of a new resilience scale: the Connor-Davidson resilience scale (CD-RISC). Depression Anxiety. 2003;18(2):76-82.

15. Yu XN, Lau JT, Mak WW, Zhang J, Lui WW, Zhang J. Factor structure and psychometric properties of the Connor-Davidson resilience scale among Chinese adolescents. Compr Psychiatry. 2011;52(2):218-24.

16. Cowden J, Crane L, Lezotte D, Glover J, Nyquist AC. Pre-pandemic planning survey of healthcare workers at a tertiary care children's hospital: ethical and workforce issues. Influenza Other Respir Viruses. 2010;4(4):213-22.

17. Byrnes YM, Civantos AM, Go BC, McWilliams TL, Rajasekaran K. Effect of the COVID-19 pandemic on medical student career perceptions: a national survey study. Medical education online. 2020;25(1):1798088.

18. Wilkes $L$, Cowin $L$, Johnson M. The reasons students choose to undertake a nursing degree. Collegian. 2015;22(3):259-65.

19. Eley R, Eley D, Rogers-Clark C. Reasons for entering and leaving nursing: an Australian regional study. Aust J Adv Nurs. 2010;28(1):6-13.

20. Kim BJ, Lee SY. A Cross-Sectional Study on the Impacts of Perceived Job Value, Job Maintenance, and Social Support on Burnout Among
Long-Term Care Staff in Hawaii. Int J Environ Res Public Health. 2021;18(2):476.

21. Santana S, Loureiro SMC. Analysing drivers and outcomes of job and professional satisfaction at health centres in Portugal. Benchmarking. 2019;26(4):1357-75.

22. Windle $\mathrm{G}$. What is resilience? A review and concept analysis. Rev Clin Gerontol. 2011;21:152-69.

23. Saleem M, Dastgeer S, Durrani AK, Saad AA, Manzoor Z, Hussain HN. Self-control Mediates the Relationship between Psychosocial Strengths and Perceived Severity of COVID-19 among Frontline Healthcare Professionals of Pakistan: A Single Center Experience. Pak J Med Sci. 2020;36(Covid19-s4):S62-s6.

\section{Publisher's Note}

Springer Nature remains neutral with regard to jurisdictional claims in published maps and institutional affiliations.
Ready to submit your research? Choose BMC and benefit from:

- fast, convenient online submission

- thorough peer review by experienced researchers in your field

- rapid publication on acceptance

- support for research data, including large and complex data types

- gold Open Access which fosters wider collaboration and increased citations

- maximum visibility for your research: over 100M website views per year

At BMC, research is always in progress.

Learn more biomedcentral.com/submissions 